\title{
Drug withdrawals from the Canadian market for safety reasons, 1963-2004
}

\section{Joel Lexchin}

B y studying drugs that have been withdrawn from the market for safety reasons, we can gain valuable insight into postmarketing surveillance as well as the process for approving new drugs. In the past decade there has been a major shift in the funding structure of the Therapeutic Products Directorate (TPD), the branch of Health Canada in charge of approving new drugs. Since 1994, pharmaceutical companies have been charged fees for each new drug they submit for approval or have on the market. By 1999 these user charges were paying for close to $70 \%$ of the cost of running the TPD. ${ }^{1}$ In return, the industry asked for action on the speed with which new drugs are approved. $^{2}$

In the United States, user fees were also tied to speedier approvals by the Food and Drug Administration (FDA). The average approval time dropped from 27 months in 1993, when user fees were instituted, to 19 months in 2001. ${ }^{3}$ Do longer review times affect subsequent withdrawals for safety reasons? Abraham and Davis compared drug withdrawals in the United Kingdom and the US in the period 1971-1992 and reported 24 withdrawals in the UK versus 9 in the US - a ratio of 2.7:1. Their explanation for the lower number in the US was that the longer period spent examining the data in the US allowed regulators there to detect serious problems before an unsafe product could be marketed. ${ }^{4}$ However, an appreciable number of FDA reviewers surveyed in the late 1990s and early 2000s thought that, since 1993, FDA standards had been getting lower and that some drugs that should not be approved were being approved.,

Looking at drugs that have been withdrawn can also pose questions about the adequacy of the clinical trials that got them approved in the first place. These trials use a highly selected group of patients: those with clear-cut evidence of the disease in question, who are not taking other products and who do not have other conditions that might interfere with an analysis of the efficacy of the product being tested. Also, drugs are tested for a relatively short time. Once drugs are approved they are used in a much wider group of people and often for a much longer period. Should there be changes in the requirements for clinical trials, or should there be mandatory postmarketing studies for certain drugs?

The TPD maintains a Drug Product Database on its
Web site that lists both active and discontinued products (see www.hc-sc.gc.ca/hpfb-dgpsa/tpd/dpt/dpd_index e.html). However, it does not identify why discontinued drugs are no longer available, nor does it have a comprehensive list of drugs that have been withdrawn from the market for safety reasons.

Identifying prescription and over-the-counter products withdrawn from the Canadian market for safety reasons between Jan. 1, 1963, the start of the modern era of drug regulation ${ }^{6}$ and May 31, 2004, proved to be quite an enterprise. It took me 4 months to find and search sources, many by hand, where such information could be found. ${ }^{4,7-12}$ This included going through every edition of the Compendium of Pharmaceuticals and Specialties (CPS) from the initial edition ${ }^{13}$ to the most recent. ${ }^{14} \mathrm{I}$ also identified drugs withdrawn for safety reasons in the UK or US from 1964 to 2000. Safety withdrawals were defined as being undertaken either voluntarily by the manufacturer or after negotiation with Health Canada. Biologics (e.g., vaccines) and natural health products were excluded. To assess the completeness of the Drug Product Database, I searched it to see if the products that I had identified were listed in it as having been discontinued.

The most striking aspect of this investigation was the lack of basic information that could be obtained from Health Canada. This public agency does not maintain a comprehensive list of drugs that have been removed from Canada because of safety concerns, nor does it have a database that would allow the construction of such a list. Although the US Federal Register no longer maintains an up-to-date list of drugs removed from the US market, ${ }^{11}$ these products can still be identified through extensive records on the FDA Web site.

I identified a total of 41 products that were withdrawn from the Canadian market potentially for safety reasons. (see online appendix). This list might not be complete. For 16 of the products on the list there is no definite information about why they were removed from the Canadian market, although they were withdrawn in either the UK or the US (or both) because of safety concerns. The manufacturer of parenteral neomycin, for example, stated that it had been removed from the Canadian market because of a lack of demand for the product. The manufacturer of urethane had no information about why the drug was no longer available. Nialamide appeared in the first (1960) and 
second (1963) editions of the CPS, with Pfizer listed as the manufacturer, but Pfizer said that it had never been marketed in Canada. Two products (benoxaprofen and troglitazone) received a notice of compliance but were never marketed in Canada.

Part of the process of identifying drugs withdrawn from the Canadian market for safety reasons involved searching the CPS to see if products removed from the UK or US market had at one time been sold in Canada, the assumption being that subsequent withdrawals in this country would have occurred for safety reasons. However, if these drugs were not sold in Canada long enough to have been listed in the CPS they would have been missed.

Only 12 of the 41 drugs were listed in the Drug Product Database as discontinued. Products withdrawn as recently as 1995 (etretinate), 1997 (dexfenfluramine and fenfluramine) and 1999 (pemoline) were not listed. No product removed before 1994 was listed.

Hepatotoxicity, cardiac problems (arrhythmias and valvular disorders) and blood dyscrasias (hemolytic anemia, agranulocytosis) were the 3 leading causes of withdrawals. Eight medications were withdrawn because of hepatotoxicity and cardiac complications, and 7 because of blood dyscrasias (see online appendix).

Long availability and wide use are not guarantee of a drug's safety. Phenylpropanolamine, a widely used decongestant, was sold in Canada for over 40 years before it was removed in May 2001. It took over 25 years (October 1970 to September 1997) before it was recognized that fenfluramine was associated with cardiac valve abnormalities. The lengthy times that it can take to identify serious safety issues should remind doctors to be cautious about prescribing any product.

Ten drugs were withdrawn between 1963 and 1972. In the next 2 decades, 6 and 7 drugs were withdrawn respectively, and 16 of the 41 withdrawals have taken place since 1993. Forty-one drug withdrawals over 4 decades is not a large number. Moreover, only a relatively small number of drugs that were approved were eventually withdrawn. In the period 1993-2002, 282 new active substances were approved; of the 16 removed, only $6(3 \%)$ were actually approved during that period. However, it is necessary to look beyond the raw numbers to judge the magnitude of the problem of unsafe drugs. Large numbers of people, including vulnerable groups, were exposed to some of these products. For example in 2000, nefazodone was the 118th mostprescribed drug in Canada, ${ }^{15}$ fenfluramine was the 190th most prescribed drug in $1996,{ }^{16}$ and pemoline was used almost exclusively in children.

Why has there been an increase in the number of drug withdrawals since 1993? There may be a number of mutually nonexclusive causes, including more sophisticated methods for recognizing serious safety issues, less stringent approval criteria and more information being available from domestic adverse drug reporting systems and foreign regulatory authorities. With regard to the last point, it is not known how much Health Canada relies on information from other jurisdictions in deciding to withdraw a product and how much it acts on information that it had collected on its own.

Information received from other regulatory bodies may well prompt quicker action in some cases; on the other hand, it is also possible that information from other countries may not confirm Health Canada's concerns and thereby delay a product's removal. Because Health Canada has not publicly identified what criteria it uses to decide when a drug should be removed, we cannot know which mechanisms account for the greater number of withdrawn products. For this among other reasons, more transparency in the drug approval and monitoring process from Health Canada would be welcome.

The Marketed Health Products Directorate (MHPD) is the part of Health Canada that collects adverse drug reaction reports through a network of 5 regional reporting centres, analyzes them, and issues warnings about safety concerns through a variety of means - Dear Healthcare Professional letters; the Canadian Adverse Reaction Newsletter; drug safety advisories; regional adverse reaction centres and an electronic mailing list $;{ }^{17}$ and changes in the product monograph.

In March 2000, the cerivastatin product monograph was amended to include a contraindication to use with gemfibrozil because of the risk of rhabdomyolysis. ${ }^{18}$ However, this change does not appear to have had much of an impact; in the 2 years before it was removed (in 2001) cerivastatin went from the 132nd most prescribed drug in the country to $82 \mathrm{nd} .{ }^{15}$ Some of this increase in prescribing might have been fuelled by promotion. In 2000 Bayer spent just under $\$ 4$ million on promotion, running 361 pages of advertising and leaving 281000 samples in doctors' offices. ${ }^{19}$

Another drug that raises questions about prescribing and the adequacy of the system for informing doctors about safety concerns is cisapride. This medication was indicated primarily for gastrointestinal reflux and abdominal bloating. As early as July 1996 Health Canada advised doctors about 5 cases of cardiac arrhythmia associated with the combination of cisapride and products that inhibit the cytochrome $\mathrm{P} 450$ enzyme system. ${ }^{20} \mathrm{~A}$ second report in early 2000 discussed 70 serious adverse drug reaction reports, including 35 involving heart rate and rhythm disorders. ${ }^{21}$ Despite these alerts and the serious nature of the reactions, during the latter half of the 1990s cisapride consistently remained among the top 40 most prescribed drugs in Canada. ${ }^{16,22}$

Was there enough information available about this drug for doctors to safely prescribe it to a wide range of patients? When cisapride was first marketed in Canada, there were 9 published randomized controlled trials; however, in none of these did more than 99 patients receive the drug, and no trial lasted longer than 26 weeks. ${ }^{23}$ Health Canada has no legislative authority to require drug companies to conduct postmarketing trials. 
In the past few years, a lack of resources has forced the MHPD to stop routinely trying to assign causality when evaluating adverse drug reaction reports. ${ }^{24}$ Another indication of possible resource problems in the MHPD is the shift in the origin of adverse drug reaction reports away from regional centres. In 1998, 31.4\% and $47.2 \%$ came from the centres and manufacturers, respectively, ${ }^{25}$ by 2003 , the percentages were $29.0 \%$ and $66.5 \% .^{26}$ Given the lack of resources and the seeming inability of safety advisories to affect prescribing, what does it say about Health Canada's priorities in fiscal year 2003-04 to put an additional \$31.2 million into speeding up the approval of new drugs and only give $\$ 2.5$ million to the MHPD? ${ }^{27}$

The construction of a list of withdrawn drugs is a first step in helping to gain a better understanding of safety issues. Based on an analysis of drugs on this list it should be evident that the current safety system is inadequate: Health Canada does not know which drugs have been withdrawn because they were unsafe; there is no systematic information about what triggers a safety withdrawal; safety warnings do not appear to affect prescribing practices; the MHPD lacks resources and does not seem in line to get them. Further research should look at topics such as how adverse drug reactions relate to decisions to remove a drug, whether faster drug approvals lead to a greater number of safety withdrawals, and how to communicate safety concerns in a more effective manner to prescribers and patients alike.

Unless the Canadian public can be assured that Health Canada is adequately monitoring the safety of marketed drugs, then confidence in the use of therapeutic products will suffer - and so will the health of Canadians.

This article has been peer reviewed.

Dr. Lexchin is Associate Professor, School of Health Policy and Management, York University, Emergency Physician, University Health Network, and Associate Professor, Department of Family and Community Medicine, University of Toronto, Toronto, Ont.

Competing interests: None declared.

\section{References}

1. KPMG Consulting LP. Review of the Therapeutic Products Programme cost recovery initiative. Ottawa: Ministry of Health; 2000.

2. Canada's Research-Based Pharmaceutical Companies. Improving health through innovation: a new deal for Canadians [press release]. Ottawa; September 2002.

3. Office of Inspector General. FDA's review process for new drug applications: a management review. Washington: Department of Health and Human Services; March 2003.

4. Abraham J, Davis C. Mapping the social and political dynamics of drug safety withdrawals in the UK and the US. Sussex: Economic and Social Research Council; 2002

5. Lurie P, Wolfe SM. FDA medical officers report lower standards permit dangerous drug approvals. Washington: Public Citizen; 1998.

6. Pugsley LI. The administration and development of federal statutes on foods and drugs in Canada. Med Serv 7 Can 1967;23:387-449.

7. Rawson NSB, Kaitin KI. Canadian and US drug approval times and safety considerations. Ann Pharmacother 2003;37:1403-8.

8. Bakke OM, Wardell WM, Lasagna L. Drug discontinuations in the United Kingdom and the United States, 1964 to 1983: issues of safety. Clin Pharmacol Ther 1984;35:559-67.

9. Bakke OM, Manocchia M, de Abajo F, Kaitin KI, Lasagna L. Drug safety discontinuations in the United Kingdom, the United States, and Spain from 1974 through 1993: a regulatory perspective. Clin Pharmacol Ther 1995;58:108-17.

10. Friedman MA, Woodcock J, Lumpkin MM, Shuren JE, Hass AE, Thompson LJ. The safety of newly approved medicines: do recent market removals mean there is a problem? 7AMA 1999;281:1728-34.

11. Lasser KE, Allen PD, Woolhandler SJ, Himmelstein DU, Wolfe SM, Bor $\mathrm{DH}$. Timing of new black box warnings and withdrawals for prescription medications. 7AMA 2002;287:2215-20.

12. Department of Economic and Social Affairs. Consolidated list of products whose consumption and/or sale bave been banned, withdrawn, severely restricted or not approved by government. Eighth issue: Pharmaceuticals. New York: United Nations; 2003.

13. Hughes FN, editor. Compendium of Pharmaceutical Specialties, 1st ed. Toronto: Canadian Pharmaceutical Association; 1960.

14. Repchinsky C, editor. Compendium of Pharmaceuticals and Specialties, 37th ed. Ottawa: Canadian Pharmacists Association; 2004.

15. The top 200 drugs of 2001. Pharm Pract 2001; 17(12):3,4,6,8,13,22.

16. The top 200 drugs of 1997. Pharm Pract 1997;13(12):29,30,2,4,6,9,40.

17. Decima Research Inc. Public opinion survey on key issues pertaining to post-market surveillance of marketed bealth products in Canada. Health Canada; 2003. Report No.: POR\# 298-02.

18. Therapeutic Products Directorate. Cerivastatin $\left(\right.$ Baycol $\left.^{\circledR}\right)$ and gemfibrozil increased risk of rhabdomyolysis - concomitant use contraindicated. Ottawa: The Directorate; 2001 July 16.

19. Targeting doctors. Toronto: Canadian Broadcasting Corporation; 2002. Available: www.cbc.ca/disclosure/archives/0103_pharm/resources.html (accessed 2005 Jan 27).

20. Cisapride: arrhythmia awareness. Canadian Adverse Drug Reaction Newsletter 1996;6(3):1, 2.

21. Cisapride (Prepulsid ${ }^{\circledR}$ ): interactions with grapefruit and drugs. Can Adverse Drug React Newsl 2000;10(1):1-3.

22. The top 200 drugs of 1999. Pharm Pract 1999;15(12):4,6,7,39-42.

23. Lexchin J. New drugs with novel therapeutic characteristics: have they been subject to randomized controlled trials? Can Fam Physician 2002;48:1487-92.

24. Lexchin J. New directions in drug approval. CMA7 2004;171:229-30.

25. Adverse drug reaction reporting - 1998. Can Adverse Drug React Newsl 1999;9(2):5.

26. Adverse reaction reporting — 2003. Can Adverse React Newsl 2004;14(2):2.

27. Improving Canada's regulatory process for therapeutic products: building the action plan. Public Policy Forum multi-stakeholder consultation, 2003 [presentation]. Available: www.ppforum.ca/ow/ow_e_05_2003/Presentation $\% 20$ _Overview_of_Action_Plan.pdf (accessed 2005 Jan 27).

Correspondence to: Dr. Joel Lexchin, 121 Walmer Rd., Toronto ON M5R 2X8; fax 416 923-9515; joel.lexchin@utoronto.ca, jlexchin@yorku.ca 